\title{
Prevalence of Newcastle Disease Virus Antibodies in Apparently Healthy Chickens in Sierra Leone
}

\author{
Abdulai Mahmood Conteh", Sheku Kenway Moiforay, Mahmud Emkay Sesay, Sanpha Kallon \\ Department of Animal Science, School of Agriculture, Njala Main Campus, Njala University, Freetown, Sierra Leone \\ Email address: \\ amconteh@jala.edu.sl (A. M. Conteh) \\ ${ }^{*}$ Corresponding author \\ To cite this article: \\ Abdulai Mahmood Conteh, Sheku Kenway Moiforay, Mahmud Emkay Sesay, Sanpha Kallon. Prevalence of Newcastle Disease Virus \\ Antibodies in Apparently Healthy Chickens in Sierra Leone. Animal and Veterinary Sciences. Vol. 8, No. 5, 2020, pp. 99-103. \\ doi: $10.11648 /$ j.avs.20200805.12
}

Received: April 24, 2020; Accepted: May 19, 2020; Published: September 9, 2020

\begin{abstract}
The study was conducted in the southern province of Sierra Leone for a period of seven months (March September 2019). The main objective of the study was to investigate the seroprevalence level of Newcastle disease antibodies in apparently healthy free-range chickens in selected chiefdoms in the Moyamba District of Sierra Leone. A total of three hundred and thirty-three chickens were included in the study. Sera samples collected were analyzed using competitive Enzyme-Linked Immunosorbent Assay (ELISA). The result of the investigation revealed an overall prevalence of 56.4\% from which $21.6 \%$ and $34.8 \%$ were male and female chickens respectively. Kaiyamba chiefdom recorded the highest antibodies (73.9\%), followed by Lower Banta (53.1\%) and Bumpe (42.3\%) chiefdoms. The difference in the prevalence of each category showed that adult female chickens were the most susceptible $(67.5 \%)$ to Newcastle disease followed by the growers $(55.8 \%)$ and adult male chickens (45.9\%). Due to the lack of Newcastle disease vaccination history in the study areas, indigenous chickens had been exposed to the disease naturally in all the chiefdoms. Raising awareness about the disease through effective extension programs and improved animal healthcare services and husbandry practices is of great importance.
\end{abstract}

Keywords: Antibodies, Free-range, Newcastle Disease, Seroprevalence, Sierra Leone, Indigenous Chicken

\section{Introduction}

Although 100\% vaccine-preventable, Newcastle disease (ND) is an acute, destructive, and infectious viral infection affecting both wild and domestic birds including humans [1, 2]. Further research has also reported the presence of the virus in unhealthy pigs and two healthy sheep in China [3] as well as reptiles as they have been reported to be susceptible to ND virus [5]. The virus belongs to the family Paramyxovirus and genus Avulavirus. Considering the virulence nature of the ND, it has been categorized into velogenic (highly), mesogenic (intermediate) and lentogenic (low) pathogenicity [6]. It infects and kills thousands of unprotected chickens in high-risk communities especially in developing countries where animal healthcare services, good animal husbandry practices coupled with farmers' knowledge are lacking and/or inadequate. It is a notifiable disease by the World Organization of Animal Health considering its huge economic impact and other unquantifiable consequences on the poultry industry and the household. It is the most important preventable disease which for many decades, has crumbled poultry production globally but with the highest negative impact in the developing world [7, 8]. ND affects all breeds and categories of chickens with a rapid mode of transmission followed by different clinical manifestations depending on the genotype of the virus [9]. In areas, where poultry production is the main economic activity and a source of livelihoods, ND is a major threat that needs multisectoral interventions. Although vaccination has been reported as the most feasible approach in controlling ND, it continues to hit and spread due to the management practices, livestock trade, lack of established structure for early detection and reporting, and the uncontrolled movement of poultry and their products. Since the first recognition of NDV in poultry in 1926 in Indonesia and the first large outbreak in England (1927), the virus has been identified in Africa, Asia, Central and South America [10-14]. The global impact and prevalence of ND are yet to be fully understood as many 
countries do not report cases. While some countries report outbreaks in commercial poultry, there are virtually no reports concerning ND prevalence in the village flocks.

In Sierra Leone, the chicken population is estimated at $4,316,349$ where $78.9 \%$ are found in the rural areas [15]. Chicken production which meaningfully contributes to the livelihoods of many farmers in the study areas is mainly composed of indigenous breeds of chickens. They are reared for diverse functions ranging from fulfilling modern and traditional needs including strengthening the: spiritual, social, cultural and economic needs of the people. Approximately $90-95 \%$ of the local chickens are managed under the traditional management system due to lack of production input (capital) and the good productive and reproductive ability of these chickens under various management and environmental conditions. The major constraints affecting farmers in the study areas are: diseases, predators, poor animal healthcare, unstructured market service, stealing and lack of support ${ }^{16}$. The most notable poultry diseases locally reported is the ND that is being implicated for the low productivity and drop in income. It is characterized by paralysis of the leg and wings, whitish diarrhea, twisted neck and circling, ruffled feathers, coughing and gasping. Transmission occurs through direct and indirect contacts, improper management of infected carcasses, trade and predation. The fact that ND has been locally reported in the study areas coupled with severe losses (loss due to mortality) and lack of control measures (annual vaccination) due to laboratory evidence, there is a need to conduct this research. Therefore, the objective of this study was to investigate the presence of antibodies against ND in unvaccinated free-range chicken populations in the Moyamba district.

\section{Materials and Methods}

\subsection{Study Site and Design}

The study on the seroprevalence of ND was accomplished in Moyamba District in the southern region of Sierra Leone. It is the largest district in the south with fourteen chiefdoms with a total population of 318,588 [15]. The district is located along latitude $7^{\circ} 59^{\prime} 58.92^{\prime \prime}$ and longitude $12^{\circ} 26^{\prime} 08.88^{\prime \prime}$ with a geographical area of $6,902 \mathrm{Km}^{2}$. Grassland/savannah and farm-bush are the main geographical features followed by a few patches of forests, rivers, streams, and lakes with high rainfall $(120-230 \mathrm{~mm})$. The major activities of livelihood include farming, fishing, mining, trading, formal job, and charcoal production. $87.5 \%$ of the population is engaged in farming activities while $77.9 \%$ engaged in some form of animal husbandry practices [15]. Poultry, goats, sheep, swine, and cattle are the main livestock rear. The southern region ranks second $(24.7 \%)$ in the country after the northern region $(48.6 \%)$ in terms of chicken rearing while Moyamba District ranks first in the southern region (32.5\%) [15].

\subsection{Sample Collection}

Out of fourteen chiefdoms in the districts, three chiefdoms (Kaiyamba, Dasse, and Kori) were randomly selected. Thirty whole blood samples per chiefdom were collected. A total of 150 samples were collected from chickens during the study. Blood samples were taken from the brachial wing in the morning and late hours of the day. Chickens above two months (grower, adult male, and female) were sampled. Five milliliters (ml) syringe and a 23-gauge sterile hypodermic needle were used to collect $1 \mathrm{ml}$ of whole blood per chicken. Blood samples collected were immediately transferred into a plane glass tube with no anticoagulant and allowed to stand to clot at room temperature (RT) for 30 minutes and centrifuged using the centrifuge machine for 10 minutes. The sera were pipetted $(1000 \mu \mathrm{l})$ and put in a $1.5 \mathrm{ml}$ cryovials, stored at $-20^{\circ} \mathrm{C}$ and transported to the laboratory in less than 12 hours.

\subsection{Detection of Antibody}

Sera samples collected from each species were analyzed for the detection of anti-NDV using competitive Enzyme-Linked Immunosorbent Assay (ELISA) ID Vet, innovative diagnostics, France. Sera samples were dispensed in uncoated sterile 96 micro-well plates (Nunc) and transferred into NDV purified antigen-coated micro-plates to avoid time lag in the incubation period using a multichannel pipette. $100 \mu \mathrm{l}$ of each positive and negative control were added into their respective wells after the addition of the $40 \mu \mathrm{l}$ dilution buffer 14 to each well. $10 \mu \mathrm{l}$ of undiluted sera samples were added into the remaining wells and covered with a plate for an incubation period of 30 minutes at RT. The plate was rinsed with wash solution $1 \mathrm{X} 3$ times, tapped hard to remove remains of fluid and added to each well $100 \mu \mathrm{l}$ of the prepared anti-NDV conjugate $1 \mathrm{X}$ and incubated for another 30 minutes at RT. The plate was rinsed 3 times, tapped hard followed by the addition of $100 \mu$ of the substrate to each well, covered and incubated in the dark for 15 minutes at RT. The reaction was stopped by adding $100 \mu \mathrm{l}$ stop solution to each well and thoroughly mixed. Ledetect 96 micro-plate reader was used to read the optical densities (OD) at $450 \mathrm{~nm}$. The percentage inhibition (PI) was calculated using the formula

$$
\mathrm{PI}=\left[\mathrm{OD}{ }_{\text {Negative Control }}-\mathrm{OD} \text { Sample } / \mathrm{OD} \text { Negative Control }\right] \mathrm{X} 100
$$

Samples tested were considered positive if $\mathrm{PI} \%$ is $>40 \%$, any sample that presented a PI\% between $40-50$ was to be retested although no sample met this criterium, while all samples that showed a PI $\%<50 \%$ were considered negative.

\subsection{Data Analysis}

The information generated was input into an excel spreadsheet, summarized and exported to Statistical Package for Social Sciences (SPSS) version 23 for final analysis. Frequency distributions and percentages were used to illustrate findings using tables and charts. Observations, interactions with farmers and personal discussion were used to back up the epidemiological findings to achieve the purpose of the study.

\section{Result}

The overall result of the study showed that $56.5 \%$ of the three hundred and thirty-three (333) sera samples tested for 
NDV were positive. $34.8 \%$ of the positive samples accounted for female chickens while $21.6 \%$ were male chickens (see figure 1).

The result presented in table 1 revealed that Kaiyamba chiefdom had the highest positive cases $(73.9 \%)$ of NDV antibodies per chiefdom followed by Lower Banta (53.1\%) and Bumpe $(42.3 \%)$ chiefdoms. The highest number of female chickens tested seropositive was observed in Kaiyamba (53.2\%), Lower Banta (41.4\%) and Bumpe (28.8\%) while Kaiyamba (20.7\%) and Bumpe (13.5\%) had the largest male seropositive cases followed by Lower Banta chiefdom (11.7\%).

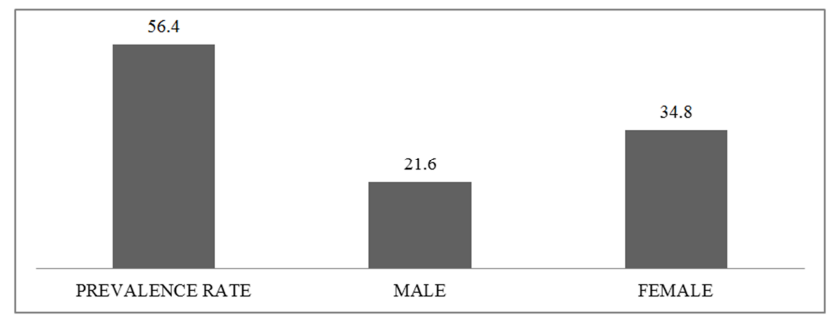

Figure 1. Overall prevalence of ND anbodies detected.

Table 1. Number of sampled chickens per chiefdom with respect to gender.

\begin{tabular}{|c|c|c|c|c|c|c|}
\hline \multirow{4}{*}{ Variables } & \multicolumn{6}{|l|}{ Chiefdoms } \\
\hline & \multicolumn{2}{|l|}{ Kaiyamba, $N=111$} & \multicolumn{2}{|c|}{ Lower Banta, $N=111$} & \multicolumn{2}{|c|}{ Bumpe, $N=111$} \\
\hline & \multicolumn{6}{|l|}{ Gender } \\
\hline & Male & Female & Male & Female & Male & Female \\
\hline No of positive tested & 23 & 59 & 13 & 46 & 15 & 32 \\
\hline$\%$ of positive tested & 20.7 & 53.2 & 11.7 & 41.4 & 13.5 & 28.8 \\
\hline
\end{tabular}

The total seroprevalence of NDV among the three categories of chickens investigated indicated that $67.5 \%$ of the chickens were adult females, $55.8 \%$ were growers and $45.9 \%$ were matured male chickens (see figure 2).

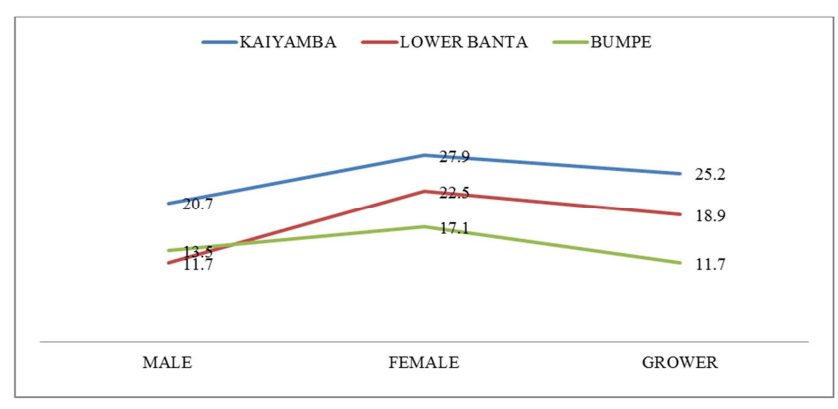

Figure 2. Categories of IC tested positive against NDV antibody.

\section{Discussion}

The result obtained in this study has for the first time revealed the presence of Newcastle disease virus (NDV) antibodies in Moyamba District. From a total of three hundred and thirty-three indigenous chickens sampled in three chiefdoms, one hundred and eighty-eight (188) showed positive for NDV antibodies representing $56.5 \%$ of the chickens. Neither the chickens sampled nor the communities in which the study was conducted had a vaccination history against ND which describes a natural infection (figure 1). Comparatively, the seroprevalence in this study was observed to be lower than that reported in Nigeria and Grenada [17, 18], but higher than that reported in Zamfara State in Nigeria $(32.5 \%)$ [19], and in a poultry farm in Oman (33.8\%) [20]. The observed high seropositivity detected during the study might be attributed to the lack of interest in the control, prevention and eradication of the diseases within the local and national context by the appropriate concerned stakeholders.

Overall, there was a high susceptibility of female chickens to ND compared to the male chickens. 116 (34.8\%) of the sampled female chickens during the study were seropositive while $72(21.6 \%)$ of the male chickens tested positive for NDV antibodies (figure 1). Therefore, the high prevalence of female chickens to ND infection particularly in the free-range management system within the period of the study have demonstrated a high susceptibility probably caused by weak immune status compared to the male chickens. According to $[21,22]$ in Ethiopia, female chickens were more vulnerable to ND compared to the male chickens, which is inconsonant with this study. This result, however, showed a discrepancy with [23] findings in Nigeria who reported high seropositivity in male chickens compared to the females. The increased prevalence level detected among female chickens could be associated with the long period of exposure to the virus, the asymptomatic characteristics of carrier chickens which make early detection of the disease very difficult or impossible and the frequent interaction with multiple susceptible hosts of both domestic and wild animals. In the study areas, female chickens were the main flock composition (parent stock) because they were mostly retained for long-term production purposes compared to the male which were most times meant for non-productive purposes (food, income, and socio-cultural or religious rites).

The result further demonstrated a widespread of ND within the three chiefdoms which signified a serious threat and concern in the poultry industry, particularly for village chicken production. The rapid and widespread potential of the disease in the studied areas was associated with the type of adopted management system and it practices; keeping of different species together that are susceptible hosts to the virus (duck, pigeon, guinea fowl or captured wild birds); the absence of or poor disease control policy; the unsupervised movement of chickens for societal, traditional, economic, and production purposes which is in agreement with [24] finding. Some of these breeds (duck, guinea fowl, pigeon) have been confirmed seropositive for ND in other studies that serve as possible hosts $[25,26]$. In addition, the likelihood for the transmission and spread of ND among local flock by rodents, 
insects, reptiles, domestic animals (cat, dog, pig) and wild carnivores of poultry (red fox) should not be oversighted.

Out of the one hundred and eleven chickens sampled per chiefdom, a large number tested positive for NDV antibodies (table 1). The highest antibody prevalence was recorded in Kaiyamba chiefdom (73.9\%), followed by Lower Banta chiefdom (53.1\%) and Bumpe chiefdom (42.3\%). Such a high prevalence of ND might be attributed to the increase in environmental and climatic conditions (hot weather, inconsistent rainfall) that cause heat stress suitable for the virus to survive as well as the lack of vaccination culture among indigenous chicken owners. Another reason might be the low level of awareness on ND among farmers, the poor method of treatment (traditional), season of the study, and the non-adherence to biosecurity principles.

Figure 2 showed the analysis in percentages of the different categories of chickens (male, female and grower) sampled in all the three chiefdoms. The highest number of antibodies was recorded in Kaiyamba chiefdom among female chickens (27.9\%), followed by the growers $(25.2 \%)$ (three-six months old) and male chickens $(20.7 \%)$. The proportion of the positive samples in Lower Banta and Bumpe were 22.5\%, 18.9\%, 13.5\% and $17.1 \%, 11.7 \%, 11.7 \%$ for female, grower, and male chickens respectively. These variations in the prevalence level of antibodies might be ascribed to many risk factors which include large flock size with common interactive characteristics, live chicken market, uncontrolled movement of chickens and their products, and the poor management of infected carcasses. The findings described in this study is similar to that of [27], who also reported ND to be transmitted via ingestion of contaminated water and feed, trade-in live birds, the introduction of live birds through gift and exchange.

ND infection was reported throughout the year although the severity of the disease fluctuates due to variable environmental conditions; poor immune status of the chickens due to inadequate feeding and the circulating viral strain. Mortality and morbidity due to ND were high between the periods of April-May and sometimes during harmattan season as chickens are normally exposed to two different climatic conditions which are in line with the findings of [28]. NDV cases normally heighten in the rainy season and in feed crisis causing the chickens to develop low immune status hence becoming defenseless. In other reports, local chickens are known to be asymptomatic especially for birds that have had a previous infection (carriers) but shed the virus which could be a source of infection to other farmers. In a similar study conducted by [29] village chickens have natural immunity against ND and therefore, can withstand the disease without any clinical manifestation thus posing a high risk to both the commercial and local poultry industry.

\section{Conclusion and Recommendation}

Newcastle disease is a highly contagious and lethal disease that causes severe economic loss, nutritional insecurity and poor social commitment among the farmers. The study has for the first time reported seroprevalence evidence of ND antibodies in free-range chickens in Moyamba District. The overall prevalence of ND detected was $56.4 \%$ where $26.1 \%$ and $34.8 \%$ were male and female chickens respectively. $73.9 \%, 53.1 \%$ and $42.3 \%$ of the chickens tested seropositive against ND were from Kaiyamba, Lower Banta and Bumpe chiefdoms correspondingly. From this study, it is important to conclude that the disease is a serious concern to village poultry farmers which underscores the need for effective and efficient control and preventive approaches. The insufficient epidemiological information, lack of adequate animal healthcare services, favorable climatic and environmental conditions for disease pathogen, poor management practices, poor awareness of farmers and lack of livestock extension services are believed to have contributed to the widespread of the disease. There is a need for an integrated disease control strategy by bringing different parties (veterinarians, farmers, medical personnel, livestock traders, extensionists, and stakeholders) into active play. An effective vaccination campaign program is highly recommended to help reduce, prevent or eradicate the disease. To have a full picture of ND, further detailed confirmatory studies are required to investigate the different strains of the virus; seasonal pattern; risk factors; knowledge, attitudes, and practices of farmers; impact at household and national levels and different control measures available in affected communities is required. Key to all, livestock extension programs should be strengthened to create awareness among chicken farmers to improve their management practices and biosecurity measures.

\section{Acknowledgements}

The authors wish to express their thanks and appreciations to all involved in the field work for the collection of specimens. We further extend our appreciations to all stakeholders in the study communities as well as the poultry farmers for their approval of and participation in the study.

\section{References}

[1] Al-Garib, S. O., Gielkens, A. L. J., and Koch, G., 2003. Review of Newcastle disease virus with particular references to immunity and vaccination. World's Poultry Science Journal, 59, 185-197.

[2] Nworie, O., Ezeifeka, G. O., Ogbu, O., Ogbu, M. A., Anyim, C., Ugwu, J. I., and Okoli, C. S., 2012. Sero-prevalence of Newcastle disease in Humans and apparently cross-breed of chickens in Nigeria. Central European Journal of $\begin{array}{lllll}\text { Experimental } & \text { Biology, } & 1 & \text { (2): } & \text { 69-73. }\end{array}$ www.scholarsresearchlibrary.comt.

[3] Chen, S., Hao, H., Wang, X., Du, E., Lui, H., Yang, T., Lui, Y., Fu, X., Zhang, P., and Yang, Z., 2013. Genomic characterization of a lentogenic Newcastle disease virus strain HX01 isolated from sick pigs in China. Virus Genes. Vol. 46 (2): 264-70.

[4] Alexander, D. J., (2000). Newcastle disease and other avian paramyxoviruses. Revue Scientifique et Technique Office in International des Epizooties, vol. 19 (2): 443-462. 
[5] OIE, 2000. Newcastle disease, Manual of standard for diagnostic tests and vaccines, $5^{\text {th }}$ Edn Office International des Epizootics (OIE), Paris, pp: 104-124.

[6] Aziz, A. G. T., and Ahmed, T. A., 2010. Serological survey of Newcastle disease in domestic chickens in Sulaimani Province. Journal of Zankay Sulaimani, 13: 31-38.

[7] Ngaji, L. W., Nyaga, P. N., Mbuthia, P. G., Bebora, L. A, and Michieka, J. N., 2010. Prevalence of Newcastle disease virus in village indigenous chickens in varied agro-ecological zones in Kenya. Livestock Research for Rural Development, 22: 1-4.

[8] Okeke, E. N., and Lamorde, A. G., 1988. Newcastle disease and its control in Nigeria, in viral disease of animals in Africa, A. Olufemi Williams and Masiga, W. N., Eds., CTA/OAU/STRC/Publication, Lagos, Nigeria, 1988.

[9] Kraneveld, F. C. 1926. A poultry disease in the Dutch East Indies. Nederlands-Indische Bladen voor Diergeneeskunde, 38: 448-450.

[10] Doyle, T. M. 1927. A hitherto unrecorded disease of fowls due to a filter-passing virus. Journal of Comparative Pathology and Therapeutics, 40: 144-169.

[11] Herczeg, J., Wehmann, E., Bragg, R. R. Travassos, D. P. M., Hadjiev, G., Werner, O., and Lomniczi, B. 1999. Two novel genetic groups (VIIb and VIIIB0 responsible for recent ND outbreaks in Southern Africa, one (VIIb) of which reached Southern Europe, Archives of Virology, vol. (144): 2087-2099.

[12] Lee, K. E., Jeon, W. J., Kwon, J. H., Yang, C. B., and Choi, K. S. 2009. Molecular epidemiological investigation of NDV from domestic ducks in Korea, Veterinary Microbiology, vol. 134 (3): 241-248.

[13] Lui, H., Wang, Z., Wang, Y., Sun, C., Zheng, D., and Wu, Y. 2008. Characterization of NDV isolated from waterfowl in China, Avian Diseases, Vol. 52 (1): 150-155.

[14] Samuel, A., Nayak, B., Paldurai, A., Xiao, S., Aplogan, G. L., Awoume, K. A., Webby, R. J., Ducatez, M. F., Collins, P. L., and Samal, S. K. 2013. phylogenetic and pathotypic characterization of NDV circulating in West Africa and efficacy of a current vaccine, Journal of Clinical Microbiology, vol. 51 (3): 771-781.

[15] SSL., 2015. Statistics Sierra Leone, Population and Housing Census. http://www.statistics.sl.

[16] Conteh, A. M., and Sesay, A. R., 2019. Current status of indigenous chicken production in Moyamba District. International Journal of Research Studies in Microbiology and Biotechnology, 5 (3): pp. 7-16. DOI: http://dx.doi.org10.20431/2454-9428.0503003.

[17] Nwanta, J. A., 2003. Field vaccination trial with Rehman, 2004. Newcastle disease virus in the Newcastle Disease Vaccine (NDV4HR) in local intestinal contents of broilers and layers. Pak. Vet. Chicken in Kaduna State, Nigeria. A PhD J., 24: 28-30. Dissertation, Ahmdu Bello University Zaria, Nigeria.

[18] Sharma, R. N., Brejeon, A., Bruyant, S., Tiwari, K., Chikweto, A., Bhaiyat, M. I., 2015. Seroprevalence of Newcastle disease, chicken infectious anemia and avian influenza in indigenous chickens in Grenada, West Indies. Journal of Animal Research. 1-5.

[19] Jibril, A. H., Umoh, J. U., Kabir, J., Saidu, L., Magaji, A. A., Bello, M. B., and Raji, A. A., 2014. Newcastle disease in local chickens of live bird markets and households in Zamfara State, Nigeria. Hindawi Publishing Corporation ISRN Epidemiology. Volume 2014, Article ID 513961, 4 pages. http://dx.doi.org/10.1155/2014/513961.

[20] Ali, A., Aini, I., Abdulrahman, O., Siti, Z. R., and Mohammed B. S., 2018. Seroprevalence of Newcastle disease virus in backyard chickens and herd-level risk factors on Newcastle disease in poultry farms in Oman. International Journal of Veterinary Science and Medicine, 6 (2): 168-191.

[21] Ohore, O. G., Ozegbe, P. C., Emikpe, B. O., and Okojie, V. E., 2002. Survey of Newcastle disease virus in apparently healthy adult Nigerian indigenous chickens (Gallus domesticus) in Ibadan using ELISA. Af $\mathrm{J}$ Clinical and Experimental Microbiology, 3: 38-40.

[22] Sadiq, M. A, Nwanta, J. A., Okolocha, E. C., and Tijjami, A. N., 2011. Retrospective (2002-2009) study of Newcastle disease (ND) cases in Avian Species in Maiduguri, Borno State, North Eastern Nigeria. International Journal of Poultry Science, 10 (1): 76-81, 2011 ISSN 1682-8356 (C) Asian Network for Scientific Information, 2011.

[23] Sarkelm, T. M Hagos, A., and Zeleke, A., 2005. Seroprevalence of Newcastle disease in local chickens in central Ethiopia. International Journal of Applied Research in Veterinary Medicine, vol. 3 (1): 25-29.

[24] Musa, U., Abdu, P. A., Qafqang, I. I., Umoh, J. U., Saidu, 1., mera, U. M., and Edache, J. A., 2009. Seroprevalence, seasonal occurrence and clinical manifestation of Newcastle disease in rural household chickens in Plateau State, Nigeria. International Journal of Poultry Science, 8 (2): 200-204, 2009 ISSN 1682-8356 C Asian Network for Scientific Information.

[25] Baokye, O. D., Emikpe, B. O., Bonnah, S. G., Adusie, K., 2016. Serological detection of Newcastel disease virus antibodies in local chickens and guinea fowls in the area of Kumasi, Ghana. Brazilian Journal of Poultry Science, 18: 87-92.

[26] Wambura, P. N., 2010. Detection of antibody to Newcastle disease virus in semi-domesticated free-range birds (Numida Meleagris and Columba livia domestica) and the risk of transmission of Newcastle disease to village chickens-short communication. Veterinarski Arhiv, 80 (1): 129-134.

[27] Oladele, S. B., Kazeem, H. M., and Raji, M. A. (1996). Survey for antibodies to infectious bursal disease, Newcastle disease and fowl pox in ducks, pigeons and guinea fowls in Zaria. Nigeria Veterinary journal, 1: 85-87.

[28] Halle. P. D., Umoh, J. U., Saidu, L., and Abdu, P. A., 1999. Prevalence and seasonality of Newcastle disease in Zaria, Niegria. Tropical Veterinary, 17: 53-62.

[29] Oyiguh, J. A., Sulaiman, S. K., Moseko, C. A., Ismail, S., Suleiman, I., Ahmed, S. J., Onate, E. C., 2014. Prevalence of Newcastle disease antibodies in local chicken Federal capital territory, Abuja, Nigeria. International Scholarly Research Notices, Hindawi Publishing Corporation, vol. 2014. 